\title{
La mujer romana y la expiación de los andróginos
}

\section{The Roman Woman and the expiation of androgynes}

\author{
Santiago Montero HERRERo \\ Universidad Complutense de Madrid \\ smontero@ucm.es
}

Fecha de recepción: 29-06-2018

Fecha de aceptación: 09-10-2018

\section{RESUMEN}

El nacimiento en la Antigua Roma de niños con rasgos sexuales masculinos y femeninos a la vez, los llamados andróginos o hermafroditas, eran considerados como un gravísimo prodigio. Su expiación, necesaria para el restablecimiento de las buenas relaciones entre los hombres y los dioses, quedó en manos exclusivamente de mujeres: ancianas, matronas y virgines.

PALABRAS CLAVE: Antigua Roma, Matrona, prodigio, expiación, andrógino

\section{ABSTRACT}

The birth in ancient Rome of children with both male and female sexual features, so-called androgynes or hermaphrodites, was regarded as a an extraordinary phenomenon. Their expiation, necessary for the restoration of good relations between men and gods, remained exclusively in the hands of women: old women, midwives and virgines.

KEY WORDS: Ancient Rome, midwife, prodigy, expiation, androgynus

Roma conoció el prodigio como una manifestación de la ruptura de la pax deorum y anuncio de calamidades y desgracias para los hombres, lo que obligaba a una inmediata expiación (procuratio prodigiorum). Dentro de la gran diversidad de tipos uno fue particularmente temible: el nacimiento de niños con malformaciones y anomalías físicas (monstrum) o con rasgos sexuales masculinos y femeninos (androgynus, semimas, hermaphroditus) ${ }^{1}$.

1 El presente atículo es una reelaboración, actualización y ampliación de mi ponencia presentada en el Congreso II mostro e il sacro. Coordinate mitico-rituali della deformità fra emarginazione e integrazione. Palazzo Massimo. Sala convegni della Soprintendenza Archeologica di Roma (Roma) 29-30 marzo 2006. Omitimos la 
La expiación o purificación del prodigio y, especialmente los de monstra y androgyna, tenía pues una particular importancia para restablecer cuanto antes el normal funcionamiento de la ciudad romana ${ }^{2}$ y así, teniendo posiblemente presente ambas anomalías biológicas, Cicerón afirma que Roma no habría podido imponerse al mundo sine summa placatione deorum (De nat. deor. III, 5). Pero, existían diferencias notables en la expiación que requería cada uno de los dos casos como también en el significado de ambas categorías de prodigia.

Los casos que conocemos de monstra -algo más de una treintena- se registran entre los años 218 y 42 a. C., siendo menos frecuentes a partir de la llamada "guerra social". Las fuentes son raramente explícitas respecto a su expiación indicando en algunos casos su cremación a cargo de los arúspices. El poeta Lucano narra cómo antes de la batalla de Farsalia, el arúspice Arruns ordenó "quemar con llamas funestas los nefandos frutos de vientres estériles" (Fars. I, 589: sterilique nefandos ex uteru fetus...). Sabemos que el nacimiento en el 209 a. C. de un niño con cabeza de elefante, junto a otros prodigios registrados ese mismo año, requirió la expiación de víctimas adultas y una supplicatio ante todos los altares (Liv. XXVII 11, 5). En otras ocasiones las fuentes señalan plegarias (Liv. XXXV 21, 3) o mencionan simplemente purificaciones si bien estas siempre dentro del conjunto de los prodigia registrados en el año.

El nacimiento de un andrógino (androgynus, semimas o semivir) se presentaba como el peor de los anuncios posibles y su temor fue en continuo aumento. Quid, ortus androgyni nonne fatale quoddam monstrum fuit?, se pregunta Cicerón (de div. I, 98). Al contrario de cuanto sucede con los monstra, para el caso del nacimiento de andróginos el ritual de expiación está mucho más documentando por las fuentes y es posible que existieran unas reglas fijas ${ }^{3}$. En casos de extrema gravedad, los decénviros y arúspices llegaron en alguna ocasión a colaborar en la ejecución de la expiación del andrógino, siempre bajo la atenta mirada del Senado y los pontífices, si bien preservando unos y otros sus respectivos ámbitos de intervención en el ritual.

La expiación constaba de dos partes claramente diferenciadas. En la primera intervenían los sacerdotes, particularmente los arúspices etruscos, para deshacerse de la criatura y expulsarla del territorio romano (agro Romani arceri). Para referirse a la ejecución, Livio emplea el verbo necari, necatus que, en la definición de Festo 190 L, y a diferencia de occidere, occisus, alude a una muerte sin violencia, es decir, sin "golpe" (sine ictus): occisum a necato distingui quidam, quod alterum a caedendo atque ictu fieri dicunt, alterum sine ictu (Breglia Pulci Doria, 1983, 81). Eran ellos los encargados de encerrar el androgynus todavía vivo en un arca y depositarlo en el mar o en el Tíber, (in mare deportare o in mare defere). A partir de aquí, se abría una nueva fase, más decisiva, en la que el Estado romano ponía la expiación en manos exclusivamente de mujeres. Por tanto, la primera parte se encarga de la eliminación (abominatio), mientras la segunda asumía la reparación y el intento de restablecer la paz con los dioses. Solo de esta forma quedaban conjurados los efectos de la pollutio sobre la civitas.

extensísima bibliografia sobre el prodigio romano y remitimos solo a la que atiende al prodigio "biológico": Sobre el monstrum es indipensable Allély, 2003 y Allély, 2004, pero debe consultarse también: Delcourt 1958; Delcourt 1966; Louis 1975; Moussy 1977; Garland, 1995; Trentin 2011; Maiuri 2012; Maiuri, 2013. Sobre el andrógino: Delcourt, 1958; Delcourt, 1966; Brisson, 1986; Brisson, 1987; Cantarella 2002; Allely 2004, 86-87, Androutsos 2006; Cid 2007; Graumann 2013.

2 En general sobre la expiación en Roma: Lake, 1937; Halkin 1953; Freyburger 1977; Freyburger, 1978; MacBain 1982; Mazurek, 2004; Berthelet, 2010; Berthelet, 2013.

3 Sobre la expiación de monstra y androgyna: Lake 1937; Halkin, 1953; Freyburger, 1977; Freyburger 1988, 501-525; Mazurek, 2004; Montero, 2008. 
Los primeros casos de andróginos son en Roma relativamente tardíos pues aparecen por primera vez en el contexto de la Segunda Guerra Púnica, concretamente en el año 209 a. C. (Liv. XXVII, 11, 1-6). Sin embargo, no se celebró entonces ningún tipo particular de expiación aunque sí una procuratio de tipo general (supplicatio y obsecratio) en la que la participación debió ser colectiva, tanto de hombres como de mujeres. Solo dos años después, en el del 207, ante el descubrimiento de un nuevo andrógino esta vez en la ciudad de Frosinone ${ }^{4}$, se buscó un remedio, un ritual expiatorio "elaborado para la circunstancia", como dice J. Champeaux $(1996,69)$. En realidad, el niño reunía las características de un monstrum y de un androgynus simultáneamente. Nació, dice Livio (XXVII, 37, 5-7), "un niño grande como si tuviese cuatro años de edad y causaba impresión no tanto por el tamaño como por la ambigüedad del sexo apenas nacido" (Frusinone natum esse infantem quadrimo parem... incertus mas an femina esset). Llamados de Etruria, los arúspices indicaron que este prodigio era "abominable y nefando" (foedum ac turpe) y que debía ser expulsado del territorio romano y después inmerso en las profundidades lejos del contacto con la tierra.

En este nuevo ritual colaboraron, como ya se ha dicho, decénviros y arúspices, junto a los pontífices, decidiéndose hacer caer el peso de la expiación sobre la mujer. En efecto, una vez eliminado físicamente el prodigio, los decénviros, siguiendo las prescripciones de los Libros Sibilinos, y los arúspices las de los libros de la Etrusca disciplina, ordenaron procesiones lustratorias para purificar la ciudad a cargo de las mujeres que recorrieron el núcleo urbano con sus cantos al tiempo que depositaban ofrendas en los templos de divinidades también femeninas como Juno, Ceres o Prosérpina. Desde esa fecha, el ritual no sufriría transformaciones apreciables. Examinemos los casos de andróginos conocidos:

209 a.C.: Liv. XXVII, 11, 4

[...] y en Sinuesa había nacido una criatura de sexo ambiguo, mitad masculino y mitad femenino, lo que vulgarmente se llama un andrógino empleando la lengua griega, que suele prestarse más a la formación de palabras compuestas ${ }^{5}$.

207 a.C.: Liv. XXVII, 37, 5-7

Cuando los ánimos se habían liberado de los temores religiosos se vieron de nuevo turbados por la noticia de que en Frosinone un recién nacido era igual que un niño de cuatro años, y no era tanto su tamaño lo sorprendente sino el hecho de que tampoco en este caso se sabía con seguridad si era varón o hembra, como había ocurrido en Sinuesa dos años antes. Pues bien, unos arúspices a los que se hizo venir de Etruria declararon vergonzoso y funesto este portento; había que sacarlo de territorio romano, lejos del contacto con la tierra, y sumergirlo en el mar. Lo metieron vivo en una caja y se lo llevaron mar adentro, donde lo arrojaron. Decretaron además los pontífices que tres grupos de nueve doncellas cada uno recorrieran la ciudad cantando un himno. Cuando estaban en el templo de Júpiter Estator aprendiendo el himno, compuesto por el poeta Livio [Andrónico], cayó un rayo en el templo de Juno Reina en el Aventino; y como los arúspices dijeron que este portento concernia a las matronas y que había que aplacar a la diosa con una ofrenda, fueron convocadas en el Capitolio por un edicto de los ediles curules las matronas que tenían el domicilio en Roma o en un radio de diez millas de la ciudad, y eligieron a veinticinco entre ellas mismas para hacerles entrega de pequeñas cantidades tomadas de sus dotes. Con la suma se hizo una jofaina de oro como presente que se llevó al Aventino, y las matronas ritualmente purificadas ofrecieron

4 Para la expiación del 207: Abaecherly, 1937; Cousin, 1942-1943; Champeaux, 1996; Mineo 2000; Guittard, 2004.

5 et Sinuessae natum ambiguo inter marem ac feminam sexu infantem, quos androgynos uolgus, ut pleraque, faciliore ad duplicanda uerba Graeco sermone appellat..., 
un sacrificio . $^{2}$

200 a.C.: Liv. XXXI, 12, 6-10

En la Sabina había nacido una criatura que no se sabía si era niño o niña, y había aparecido otro chico, de dieciséis años ya, también de sexo incierto... Se consideró que todos estos seres eran monstruosos y aberrantes, fruto de una naturaleza que pervertía las especies; fueron rechazados con particular horror los hermafroditas dando orden de echarlos al mar inmediatamente, como se había hecho poco antes, durante el consulado de Gayo Claudio y Marco Livio [207 a. C.], con un engendro parecido. A pesar de todo, se pidió a los decénviros que consultasen los Libros acerca de aquel portento. Ateniéndose a ellos, los decénviros prescribieron las mismas ceremonias que se habían realizado hacía poco a raíz del fenómeno similar. Mandaron, además, que tres coros de nueve doncellas recorrieran la ciudad cantando un himno a Juno Regina y le llevaran un presente. El cónsul Gayo Aurelio se ocupó de que se cumpliese todo ello de acuerdo con el dictamen de los decénviros. El himno lo compuso en esta ocasión Licinio Tégula, igual que la otra vez lo había hecho Livio [Andrónico], según recordaban los senadores ${ }^{7}$.

186 a.C.: Liv. XXXIX, 22, 5

Más o menos por la misma fecha llegó también la noticia de Umbría de que se había encontrado un hermafrodita de unos doce años de edad. Para conjurar semejante prodigio dieron orden de alejarlo del territorio romano y darle muerte cuanto antes ${ }^{8}$.

Obs.3: En Umbría se halló un hermafrodita de unos doce años y se le dio muerte siguiendo instrucciones de los arúspices ${ }^{9}$.

142 a.C.: Obs. 22.

Un andrógino que había nacido en Luna fue arrojado al mar siguiendo instrucciones de los arúspices ${ }^{10}$.

6 Frusinone natum esse infantem quadrimo parem nec magnitudine tam mirandum quam quod is quoque, ut Sinuessae biennio ante, incertus mas an femina esset natus erat. id uero haruspices ex Etruria acciti foedum ac turpe prodigium dicere: extorrem agro Romano, procul terrae contactu, alto mergendum. uiuum in arcam condidere prouectumque in mare proiecerunt. decreuere item pontifices ut uirgines ter nouenae per urbem euntes carmen canerent. id cum in louis Statoris aede discerent conditum ab Liuio poeta carmen, tacta de caelo aedis in Auentino lunonis reginae; prodigiumque id ad matronas pertinere haruspices cum respondissent donoque diuam placandam esse, aedilium curulium edicto in Capitolium conuocatae quibus in urbe Romana intraque decimum lapidem ab urbe domicilia essent, ipsae inter se quinque et uiginti delegerunt ad quas ex dotibus stipem conferrent; inde donum peluis aurea facta lataque in Auentinum, pureque et caste a matronis sacrificatum.

7 iam animalium obsceni fetus pluribus locis nuntiabantur: in Sabinis incertus infans natus, masculus an femina esset, alter sedecim iam annorum item ambiguo sexu inuentus; Frusinone agnus cum suillo capite, Sinuessae porcus cum capite humano natus, in Lucanis in agro publico eculeus cum quinque pedibus. foeda omnia et deformia errantisque in alienos fetus naturae uisa: ante omnia abominati semimares iussique in mare extemplo deportari, sicut proxime C. Claudio M. Liuio consulibus deportatus similis prodigii fetus erat. Nihilo minus decemuiros adire libros de portento eo iusserunt. Decemuiri ex libris res diuinas easdem quae proxime secundum id prodigium factae essent imperarunt. Carmen praeterea ab ter nouenis uirginibus cani per urbem iusserunt donumque lunoni reginae ferri. ea uti fierent $C$. Aurelius consul ex decemuirorum responso curauit. Carmen, sicut patrum memoria Liuius, ita tum condidit P. Licinius Tegula.

8 Sub idem tempus et ex Umbria nuntiatum est semimarem duodecim ferme annos natum inuentum; id prodigium abominantes arceri Romano agro necarique quam primum iusserunt.

9 In Umbria semimas duodecim ferme annorum inventus aruspicumque iussu necatus.

10 Lunae androgynus natus praecepto aruspicum in mare deportatus. 
Oros. V 4, 8

Durante el consulado de Lucio Cecilio Metelo y Quinto Fabio Máximo Serviliano, entre otros fenómenos, se vio en Roma un andrógino; por mandato de los arúspices fue arrojado al mar; pero la realización de esta infame expiación no sirvió de nada, ya que se originó de pronto una peste tan grande que en un primer momento no bastaban y después incluso faltaban los encargados de realizar las exequias. Como consecuencia, quedaron sin vivos y llenas de muertos incluso casas ilustres; dentro, enormes herencias, pero ni un solo heredero en absoluto ${ }^{11}$.

133 a.C.: Obs. $27 a$

En el campo Ferentino nació un andrógino y fue arrojado al río. Veintisiete vírgenes purificaron la ciudad cantando ${ }^{12}$.

125 a.C.: Flegón de Trales, Mirabil.10, 1.

También nació en Roma un andrógino, cuando era arconte en Atenas Jasón y cónsules en Roma Marco Plautio [y Sexto Carminio Hipseo y Marco Fulvio Flaco]. Por cuya causa el Senado ordenó que los sacerdotes dieran lectura a los oráculos de la Sibila; y ellos propiciaron y recitaron los oráculos ${ }^{13}$.

122 a.C.: Obs. 32

En el foro de Vesano nació un andrógino y fue arrojado al mar ${ }^{14}$.

119 a.C.: Obs. 34.

En el territorio romano fue hallado un andrógino de ocho años y fue arrojado al mar. Tres grupos de nueve vírgenes cantaron por la ciudad ${ }^{15}$.

117 a.C.: Obs.36

En Saturnia se encontró un andrógino de diez años y fue arrojado al mar. Veintisiete vírgenes purificaron con sus cantos la ciudad ${ }^{16}$.

104 a.C.: Obs.43.

[se omite el prodigio]. De acuerdo con la respuesta de los arúspices, el pueblo donó una ofrenda a Ceres y Prosérpina. Veintisiete vírgenes llevaron ofrendas cantando ${ }^{17}$.

11 L. Caecilio Metello Q. Fabio Maximo Serviliano consulibus inter cetera prodigia androgynus Romae visus iussu haruspicum in mare mersus est. Sed nihil impiae expiationis procuratio profecit; nam tanta subito pestilentia exorta est, ut ministri quoque faciendorum funerum primum non sufficerent deinde non essent; iamque etiam magnae domus vacuae vivis plenae mortuis remanserunt: largissimae introrsum hereditates et nulli penitus heredes.

12 In agro Ferentino androgynus natus est in flumen deiectus. Virgines ter novenae canentes urbem lustraverunt.

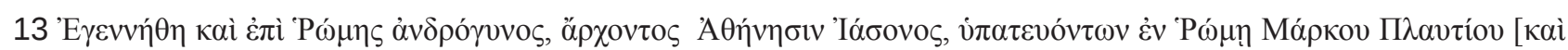

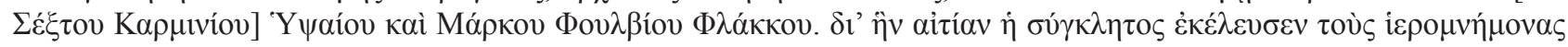

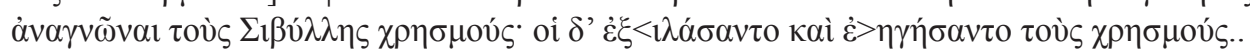

14 In foro Vessano androgynus natus in mare delatus est.

15 Androgynus in agro Romano annorum octo inventus et in mare deportatus. Virgines ter novenae in urbe cantarunt.

16 Saturniae androgynus annorum decem inventus et mari demersus. Virgines viginti septem urbem carmine lustraverunt.

17 Aruspicum responso populus stipem Cereris et Proserpinae tulit. Virgines viginti septem dona canentes tulerunt. 
99 a.C.: Obs. 46

[se omite el prodigio] El pueblo ofreció un óbolo a Ceres y Prosérpina, las matronas objetos de valor y las vírgenes llevaron ofrendas. Se ejecutó un canto a cargo de veintisiete doncellas. Se ofrecieron dos estatuas de ciprés a Juno Regina ${ }^{18}$.

98 a.C.: Obs. 47

Androgynus in mare deportatus.

97 a.C.: Obs. 48.

Se celebró una supplicatio en Roma porque había sido hallado un andrógino y fue arrojado al mar... Se erigieron estatuas de ciprés a Juno Regina por mediación de veintisiete vírgenes que purificaron la ciudad ${ }^{19}$.

95 a.C.: Obs. 50

En Urbino nació un andrógino que fue arrojado al mar²0.

92 a.C.: Obs. 53

En Arretium fueron encontrados dos andróginos... el pueblo ofreció un óbolo a Ceres y Prosérpina. Veintisiete vírgenes purificaron la ciudad cantando ${ }^{21}$.

90 a.C.: Diod. XXXII 12. De mismo modo se cuenta que en Nápoles y en otros lugares han sucedido estos casos asombrosos. No que las dos naturalezas masculina y femenina hayan sido compuestas juntas en un tipo biforme, cosa esta imposible, pero si que la naturaleza haya diseñado erróneamente las partes del cuerpo para confundir y engañar a los seres humanos. Por esta razón también nosotros hemos considerado que tales casos asombrosos merecían ser registrados, no para deleitar sino para ser de utilidad a los lectores. Muchos, en efecto, convencidos de que se trata de prodigios caen en un temor supersticioso: y no digo solo individuos concretos sino los pueblos y las ciudades. Al inicio de la Guerra Mársica, se narra, había un itálico que vivía cerca de Roma, cuya mujer era similar a los seres andróginos de los que ya se ha hablado. Él hizo la denuncia al senado, el cual, presa de temor supersticioso y dejándose convencer por los arúspices etruscos, dispuso que la mujer fuese quemada viva. Ella, que tenía una naturaleza común a la de todos y no era en verdad un ser monstruoso, encontró una muerte inmerecida simplemente porque se ignoraba cuál fuese su enfermedad.

45 d.C. Flegón I, 6. Y en Antioquía junto al río Meandro nació un andrógino, cuando era arconte en Atenas Antípatro y en Roma eran cónsules Marco Vinicio y Titio Estatilio Tauro, que tenía por sobrenombre Corvino. Una doncella de padres ilustres que contaba trece años de edad era pretendida por muchos, pues era de apariencia hermosa. Cuando fue entregada en matrimonio a quien los padres querían, al llegar el día de la boda, cuando se disponía a salir de la casa le sobrevino de forma repentina un dolor muy fuerte y lanzó un grito de dolor. Cuando sus familiares la recogieron la cuidaban como si tuviera dolores de vientre y cólico intestinal; como la afección duró tres días seguidos y el dolor causaba incertidumbre a todos, pues los dolores no remitían ni de día ni de noche, y como además la habían atendido los médicos de la ciudad y no habían sido capaces de encontrar ninguna causa de la enfermedad, al cuarto día con las primeras luces, cuando los dolores se volvieron más acuciantes, gritando con grandes gemidos, le salieron órganos masculinos, y la muchacha se convirtió en hombre.

18 Populus stipem, matronae thesaurum, et virgines dona Cereri et Proserpinae tulerunt. Per virgines viginti septem cantitatum. Signa cupressea duo lunoni Reginae posita.

19 Supplicatum in urbe quod androgynus inventus in mare deportatus erat...cupressea simulacra lunonis Reginae posita per virgines viginti septem quae urbem lustraverunt.

20 Androgynus Urbino in mare deportatus.

21 Arretii duo androgyni inventi... populus Cereri et Proserpinae stipem tulit. Virgines viginti septem carmen canentes urbem lustraverunt. 
Un tiempo después fue conducida a Roma a presencia de Claudio César; y este a causa de esta señal consagró un altar en el Capitolio a Zeus Protector de males.

53 d.C. Flegón, I, 7. También nació un andrógino en Mevania, una ciudad de Italia, en el albergue de Agripina Augusta, cuando era arconte en Atenas Dionisodoro y cónsules en Roma Décimo Junio Silano Torcuato y Quinto Haterio Antonio. Pues a una doncella de nombre Filótide, de procedencia esmirnea, madura para el matrimonio, cuando ya había sido entregada por sus padres a un hombre, le salieron los órganos masculinos y se convirtió en hombre.

54 d.C.: Tac. Ann. XII 64, 1.

En el consulado de Marco Asinio y Manio Acilio se supo por repetidos prodigios que se anunciaban cambios hacia peor en el Estado [...] se produjeron partos humanos de seres biformes, y nació un cerdo con garras de gavilán ${ }^{22}$.

Los andróginos no aparecen de forma regular, pues mientras del 209 al 142 se registran cinco, del 133 al 90 se conocen doce. B. MacBain $(1982,132)$ cree que esta mayor frecuencia se explica por la creciente intervención de los arúspices en la religión romana, así como por las inquietudes de las aristocracias etruscas durante la crisis agraria y social. En dos ocasiones (142 y 119 a. C.) el andrógino aparece como único prodigio; en los restantes casos acompañado de otros. Se trata de un tipo de prodigio muy repartido geográficamente por el territorio itálico, pues se registra no solo en Roma (142, 125, 97 a. C.) Sino en Sinuesa, Frosinone, la Sabina, Umbría, Luna, ager Ferentino, Vessano, ager Romanus, Saturnia, Urbino, Arretium y Nápoles. Debemos constatar, pues, que dicho prodigio se ha registrado solo tres veces en Roma y una en el ager Romanus, mientras se conoce sobre todo en el territorio de las ciudades aliadas independientes, latinas o itálicas. Si el prodigio del año $45 \mathrm{~d}$. C. en la ciudad de Antioquia del río Meandro se trataba de un andrógino, como sostiene Flegón, y no de un cambio de sexo, se confirmaría la aparición del fenómeno en las provincias ${ }^{23}$. Fijémonos también en que en algunos casos el hermafrodita se descubre no en el momento de su nacimiento, sino cuando contaba ya ocho años (119 a. C.), doce años (186 a. C.) o incluso siendo adulto (90 a. C.). Un nacimiento monstruoso constituía para la familia una gran desgracia y conociéndose cuál iba a ser su suerte en manos de los arúspices era preferible ocultarlo o, al menos, guardar silencio.

Del ritual expiatorio del 125 a. C. con motivo del nacimiento de un andrógino da cuenta Flegón de Trales, liberto del emperador Adriano (Breglia Pulci Doria 1983; Doroszewska 2013). Recoge en su obra Peri thaumasíon dos oráculos griegos transmitidos por la Sibila de

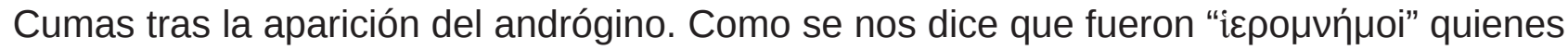
por orden del Senado leyeron los oráculos de la Sibila y que fueron ellos tambien quienes los "propiciaron y recitaron" no podemos sino pensar en los decénviros y los Libros Sibilinos. Dichos oráculos puestos en boca de la Sibila, que algunos estudiosos fechan en ese año, pero otros en época augústea aunque utilizando materiales de época silana (Breglia Pulci Doria 1983, 367), revelan los rituales expiatorios que deben seguirse para neutralizar la amenaza del andrógino y, salvo algunos detalles, no difieren mucho de los ejecutados en las

22 M. Asinio M'. Acilio consulibus mutationem rerum in deterius portendi cognitum est crebris prodigiis... biformis hominum partus et suis fetum editum cui accipitrum ungues inessent.

23 También Flegón I, 8 cita otro caso registrado en época neroniana en Epidauro: "Y otro andrógino nació por ese mismo tiempo en Epidauro, hijo de padres sin recursos, que se llamaba antes Sinferusa, y cuando se convirtió en hombre se llamó Sinferon, y pasó su vida cuidando jardines". En realidad, este caso como los del 45 y 53 d.C. mencionados también por Flegón de Trales y recogidos en nuestro listado, paracen tratarse de cambios de sexo más que de androginia. Sin embargo, como señala Allély $(2003,136)$ : "Pour les Romains, il s'agissait d'un même phénomène". 
ceremonias del 207 y del 200 a. C. La Sibila comienza refiriéndose precisamente al aspecto que trato de poner de relieve en este trabajo, es decir, a la mujer en cuanto generadora del prodigio, responsable, por tanto, de muchas de las calamidades que se abaten sobre Roma: "Afirmo, en efecto, que un día una mujer / dará a luz un andrógino que tenga todo masculino,/ y femenino aquello que muestran las mujeres niñas" (Flegonte 257 FGH 36.10 (vv. 4-5).

Una divinidad femenina, mencionada solo como anassa theà, quizá la Moira, es quien revela el ritual expiatorio que es necesario celebrar en honor de Deméter y la "casta Perséfone". El oráculo alude a una ofrenda de dinero (“...tras haber reunido un tesoro de monedas en uno solo"): el término griego thesaurós, equivalente al latino stips está en consonancia con las ofrendas que las matronas donaban a las diosas desde los tiempos de la Segunda Guerra Púnica para neutralizar la amenaza del prodigio. Se menciona también el sacrificio de 27 toros (el mismo número que el de virgines) si bien no sabemos a qué divinidad eran destinados y se ordena que sean las jóvenes (quizá las 27 virgines mencionadas) las que cumplan, siguiendo el ritual griego (achaistí), un sacrificio de vacas blancas en honor de la athanáten basilíssan. Tanto este epíteto como la elección de las víctimas sacrificiales se ajustan bien a Juno, diosa que juega un destacado papel en las placationes del 207 y del 200 a. C. Se mencionan, en fin, ofrendas de luces y regalos para Démeter y libaciones sin vino por parte de ancianas (graiai).

En el segundo oráculo se mencionan ofrendas de vestidos en honor de Perséfone pero también un sacrificio y un himno "según las leyes patrias" (patríoisi nomoisi) en honor de la diosa Hera, todo ello siempre a cargo de las mujeres.

El protagonismo que asume la mujer en las procesiones, en las ofrendas, en los cantos y en las danzas o en los sacrificios lustratorios es evidente. Es significativo que las mujeres sean divididas en grupos de edad (vírgenes, matronas, ancianas) para que cada uno de ellos desarrolle la particular misión que se les ha encomendado. Son ellas las que en 207 integran una procesión, de carácter lustratorio destinada a purificar el suelo de Roma de la mancha que comporta todo andrógino. Partiendo del templo de Apolo en el Campo de Marte entraba en la ciudad por la Puerta Carmental, atraviesa el Foro y por el Vicus Tuscus llega finalmente el templo de Juno Regina sobre el Aventino. Como hemos visto, la procesión (pompa) se repite al menos en 200, 133, 119, 117, 104 y 92.

Breglia Pulci Doria $(1983,146)$, atendiendo a que la procesión femenina pasaba por Ios templos de Fortuna y de Mater Matuta y después cerca del templo de Flora para terminar en el de Juno, concluye que "I' itinerario della processione stessa, sembra in un certo senso, per quanto possa essere obbligato, sottolineare il valore 'matronale' della ceremonia, e come il suo scopo fosse sopratutto quello di pacificarsi con una dea poliade e della nascita".

De los tres grupos de edad, las vírgenes sobresalen por su protagonismo en el ritual frente a las matronas y ancianas. En la citada procesión, en un momento dado, danzan sosteniendo una cuerda (per manus reste data), en la que se ha creído reconocer un lazo místico que materializa la "homogénéité du groupe" (Champeaux 1996, 86). Pero su protagonismo se explica sobre todo por la composición de coros $(200,125,119,117,104$, 99, 97, 92 a. C.) en tres grupos de nueve muchachas (119: ter novenae; 200: ter novenis) para cantar himnos. Augusto recurrirá a estos coros en la celebración de los Ludi Saeculares del año 17 a. C. encomendando la composición del himno al poeta Horacio, pero mientras en este caso los coros son de "muchachos y muchachas", en los ocho casos en los que intervienen coros en la ceremonia expiatoria del andrógino participan únicamente virgines. Ya en el 190 a. C. se organizaron coros de "diez jóvenes nacidos libres y diez doncellas, todos ellos con el padre y la madre vivos", pero ningún andrógino se había registrado en aquel año (Liv. 37, 3, 6). 
Junto a las mujeres figuran sacrificios de víctimas hembras. Al concluir la procesión (pompa) se inmolan dos terneras blancas sobre un altar ante el templo de Juno: ibi duae hostiae ab decemuiris immolatae. Como hemos visto antes, en la consulta efectuada en 125, los Libros Sibilinos prescribían el sacrificio de vacas: "espléndidas de hermosos cuernos y blancas crines sacrifiques, las que / en vuestra decisión sean las más destacadas en hermosura". Se insiste además en el oráculo en que sean las doncellas, las matronas o las ancianas (v. 23: graiai) las que ejecuten los sacrificios, algo llamativo teniendo en cuenta la tradicional marginación de la mujer romana del rito sacrificial. También Livio (XXVII $37,10)$ emplea la expresión pure et caste a matronis sacrificatum para dar a entender la participación de las matronas en el ritual.

Otro aspecto muy significativo son también los regalos, ofrendas o donativos. Son hechos solo por las matronas, de su propio pecunio, y siempre en beneficio de divinidades femeninas. En el 207, convocadas en el Capitolio por los ediles curules, las matronas eligen a veinticinco de ellas para entregar las "pequeñas cantidades tomadas de sus dotes" (stipem ex dotibus conferre) con las que se adquirió una jarra de oro para Juno (donum peluis aurea). Se trata de una colecta muy excepcional si recordamos que ocho años antes, en el 215, había sido promulgada la lex Oppia que limitaba el lujo y los objetos de oro a las matronas y sobre todo que, por su elevado coste, el Estado romano venía sufragando hasta entonces las ofrendas de oro (Lanuvium: 218 o Capitolio en 217 a.C.). En el 200, Livio menciona dona a Ceres y Prosérpina. En el oráculo recogido por Flegón (125 a. C.) se prescribe, como hemos visto, reunir "un tesoro de monedas" para "la muy veneranda Deméter y la casta Perséfone". En otras ocasiones, como en el año 99 a. C., se menciona la ofrenda a Ceres y Prosérpina de un thesaurus por parte de las matronas y de dona por parte de las virgines que, además, entonan un canto en honor de ambas diosas. En la lustratio prodigiorum del 92 a. C. se menciona una stips para Ceres y Prosérpina (probablemente a cargo de las matronas, aunque no sean mencionadas). En el capítulo de las ofrendas, por tanto, son también las mujeres -matronas o vírgenes- las que soportan los gastos económicos en solitario.

Por último la "feminización" del ritual expiatorio del andrógino comporta que sean exclusivamente divinidades femeninas a quienes vaya dirigido. Son tres: Juno (207, 200, 97 a. C., invocada casi siempre como Regina), Ceres / Deméter, y Prosérpina / Perséfone (la madre y la hija: 125, 104, 99, 92 a. C.). Sus templos y sus estatuas de madera de ciprés son mencionados expresamente.

En términos generales, puede decirse que mientras la eliminación (abominatio) del andrógino corría a cargo de los arúspices etruscos y los libros de la etrusca Disciplina, el ritual femenino era supervisado por los decénviros y su colección oracular (Scheid, 1988; Caerols, 1991; Monaca, 2005), todo ello bajo el atento control de los pontífices y senadores. No obstante hay que tener presente, como tuve ocasión de señalar en otro trabajo, la constante observación y la denuncia que los arúspices hacían de las costumbres morales de la mujer romana (Montero, 1993). Es significativo que cuando cae un rayo en el templo de Juno Regina durante la ceremonia expiatoria del andrógino del 207 el responsum de los arúspices concluía: prodigiumque id ad matronas pertinere (Liv. XXVII, 37, 8).

Deberíamos preguntarnos por las razones por las que los tres colegios sacerdotales, recomendaban, quizá de común acuerdo, una expiación para los monstra de tipo general, apenas mencionada por las fuentes, y otra para los androgyna, muy específica, que recaía, exclusivamente, sobre la mujer.

No cabe duda de que los dioses romanos, al menos en los primeros tiempos, se servían de las matronas -a través de los partos de monstra y androgyna- para anunciar a la comunidad ciudadana su cólera por la transgresión del pacto religioso. Advertían 
de la interrupción de la pax deorum recurriendo a la capacidad reproductiva femenina, pero al poner a la mujer en contacto con estos seres a los que trae al mundo quedaba inmediatamente contaminada por ellos. Al menos durante el período republicano los partos eran observados con mucha atención por las autoridades locales y sacerdotales. El niño, apenas nacido, no podía presentar ninguna malformación física dado que, de lo contrario, entraba inmediatamente en la categoria del monstrum. Tampoco podía presentar deformaciones de los órganos externos o un sexo no definido puesto que se le identificaba con el andrógino. Incluso un aborto era objeto de expiaciones por parte de los arúspices por su proximidad a la categoría religiosa de monstrum. De igual forma, un nacimiento múltiple, superior a tres hijos, también era considerado un prodigio (Dasen, 2003). Sin embargo, ninguno tan grave como el alumbramiento de un andrógino. Todo ello explica que al menos durante los dos últimos siglos de la República, la mujer fuera gradualmente considerada por magistrados y sacerdotes como "generadora" o "transmisora" de monstra y andróginos y, por tanto como un ser impuro, correspondiendo solo a ella su expiación.

No obstante, si dirigimos nuestra atención al tipo de expiación, se desprende que Roma no consideró de igual forma el nacimiento de monstra y el de androgyma. A. Allély sostiene en un magnífico estudio que en el caso de los monstra, es decir, de niños que nacían con malformaciones físicas, la actitud del Estado no era muy drástica y el fenómeno (sobre todo en los casos en los que faltaba algún miembro al recién nacido) no suscitaba tanta preocupación como en el caso de otros prodigios. Lo mismo sucedía si el infans nacía con rasgos propios de animales ya que se sabía que de la unión de un hombre y un animal no podía nacer nada. Por ello, concluye la estudiosa francesa, tampoco nostros debemos "attribuir une place trop importante à ces prodiges" (Allély 2003, 144).

Por el contrario, el andrógino, definido por J. Champeaux como "souillure, éminemment contagieuse", que "se transmet par contact matériel, par le seul toucher" (Champeaux 1996, 78-79), reunía según los arúspices y los libros de la etrusca Disciplina características muy graves, siendo el criterio de estos adivinos el que acabó imponiéndose en Roma a partir de la Segunda Guerra Púnica. Se trataba de seres con características masculinas y femeninas a un tiempo, seres ambiguos desde el punto de vista sexual que rompían con la diferenciación biológica que existía entre el hombre y la mujer y con lo que la sociedad esperaba de cada uno de los dos géneros. En cierta forma, el Estado romano mostraba su temor a la indiferenciación: natum ambiguo nos dice Livio refiriendose al prodigio del 209 a. C. Además de esta característica, el andrógino era infértil y esto preocupaba en tiempos de la Segunda Guerra Púnica o de la Guerra Social, cuando la demografía era muy baja en Roma como consecuencia de las numerosas masacres. Creo que el epicúreo Lucrecio se hace eco bien de ambas preocupaciones, indefinición y esterilidad:

Numerosos portentos en aquella época se esforzó la tierra en crear, formados con rostro y miembros extraños: el andrógino, medio entre los dos sexos, ni el uno, ni el otro, alejado de ambos; unos seres privados de pies, por el contrario, otros desprovistos de manos, o también seres mudos, sin boca, y los que se hallaban ciegos y sin ojos o cuyos miembros se adherían pegados a todo el tronco de modo que no podían realizar cosa alguna, ni encaminarse a parte alguna, ni tomar lo que les era indispensable. Los restantes monstruos y portentos similares los producía la tierra, pero en vano, ya que la naturaleza les impidió el crecimiento y no pudieron alcanzar la ansiada flor de la edad, ni encontrar el alimento, ni unirse en el placer de Venus. Vemos, sin duda, que muchos factores deben concurrir en los seres para que, al reproducirse, puedan propagar la especie: primero deben existir alimentos, luego un conducto en el cuerpo por donde la semilla genital pueda difundirse por los miembros relajados, y, para que la hembra pueda unirse al macho, poseer los órganos con los cuales uno y otro truequen entre si goces compartidos ( $\mathrm{V}, 837-856)$. 
Desde el punto de vista de la cosmología etrusca, los andróginos no eran muy diversos de los injertos, técnica de reproducción vegetal estudiada por D. Segarra desde una perspectiva histórico-religiosa: "El injerto consistía, pues, en una actividad meticulosa y delicada, sujeta a preceptos y precauciones de orden técnico y religioso simultáneamente que traducían un efectivo temor del hombre ante su propia intrusión en el mundo natural...." (Segarra 2005, 179; Segarra 2006). Para injertar, se debían tener en cuenta preceptos y cautelas de tipo religioso y los arúspices buscaban cuidadosamente la afinidad entre el árbol y el esqueje que iba a ser injertado con el fin de que el rusticus no produjese un ser contrario a las leyes de la naturaleza. No está permitido por la religión, dice Plinio, mezclar cualquier especie a través del injerto (Neque omnia insita misceri fas est: $N H \mathrm{XV}, 57$ ) señalando que estos adivinos prohibían intertar árboles espinosos.

En el ámbito de los monstra, los niños y niñas (pueri y puellae), si bien nacidos con malformaciones físicas, poseían un sexo definido. Los andróginos, en cambio, carecían de esta definición sexual, como se desprende de las fuentes (209: inter marem ac feminam; 207: incertus mas an femina; 200: incertus infans; 186: semimas; 54 d.C.: biformis hominum). Eran como un injerto masculino en un cuerpo femenino, y constuían por ello una grave amenaza para la continuidad de la especie humana y un atentado contra el orden establecido por los dioses.

La mujer etrusca, romana o itálica estaba obligada a expiar un tipo de prodigio que ella misma había traído al mundo, una mancha con la que podía contagiar a la ciudad y de la que ella misma se había contagiado. Es ella, la virgo, la matrona o la anciana -y no el hombre- quien debía restablecer por tanto la normalidad biológica de Roma a través de un ritual expiatorio bien establecido por los colegios sacerdotales masculinos. Eso explica no solo su activa presencia en el ritual lustratorio de los andróginos sino también que las ofrendas y plegarias se dirigieran exclusivamente a divinidades femeninas como Ceres o Prosérpina, pero, sobre todo, a Juno, cuya estrecha vinculación con la función de la fecundidad y su protección de la descendencia del pueblo romano eran bien conocidas.

Existen muchas razones para pensar que a partir del cambio de era, Roma acabó abandonando la consideración de los andróginos como prodigios y, por tanto, su doble ritual expiatorio. En primer lugar no tardaron en levantarse voces contrarias al cruel ritual de la abominatio del andrógino como la del historiador griego Diodoro (h. 49 a. C.), quien no duda en calificarlo de "superstición" mostrándose convencido de que se trataba solo de un desorden o una anomalía física de los órganos genitales ${ }^{24}$. A este tipo de opiniones vino a sumarse también más tarde la de los cristianos, como Orosio a propósito del andrógino del año 142 a. C. Plinio, en un pasaje reproducido por Gelio (N.A. IX, 4, 16), nos dice que, en su tiempo, los andróginos no son considerados ya como prodigia sino que se han hecho deliciae, es decir, objeto de placer (aunque quizá haya que entender, que eran explotados con fines sexuales): Gignuntur et utriusque sexus quos hermaphroditos vocamus, olim androgynos vocatos et in prodigiis habitos, nunc vero in deliciis (NH VII 34). Sabemos que en el Imperio ni jurisconsultos ni los médicos los trataban ya como prodigia (Crifò 1999;

24 Diodoro fr. 32, 12, después de mencionar el andrógino del 90 comenta lo siguiente: "Y poco tiempo después también en Atenas se dice que sucedió algo similar y que por ignorancia del fenómeno una persona fue quemada viva.... El hecho es que teniendo cada uno de los dos géneros un único órgano sexual, con su propia identidad, sin embargo, a las características suyas propias se añade una anomalía, algo mal diseñado, que trae a engaño al observador superficial; por ejemplo, a los genitales femeninos viene añadido algo que se asemeja al miembro viril o, en el caso opuesto, a los genitales masculinos viene unida una apariencia de órgano femenino. Este discurso sirve también para todos los seres vivientes y si bien nacen muchos prodigios y de todo tipo, estos no están sujetos al crecimiento y a un desarrollo completo. $Y$ todo esto sea dicho como remedio a los temores supersticiosos". 
Péter, 2001; Cantarella 2005; Vallar 2013). Y de hecho, aunque en el año 54, en época neroniana, todavía se descubre un andrógino, Tácito (que, por cierto, se sirve de una perífrasis: biformis hominum) no menciona ya su expiación.

\section{BIBLIOGRAFÍA}

Abaecherly Boyce, A. (1937), "The expiatory rites of 207 B. C.", TAPhA, 68, 157-171.

Allély, A. (2003), "Les enfants malformés et considerés comme prodigia à Rome et en Italie sous la République", REA, 105, 1, 127-156.

Allély, A. (2004), "Les enfants malformés et handicapés à Rome sous le Principat", REA, $106,1,73-101$.

Androutsos, G. (2006), "Hermaphroditism in Greek and Roman antiquity", Hormones, 5, 214-217.

Berthelet, Y. (2010), "Expiation, par les autorités romaines, de prodiges survenus en terre alliée: Quelques réflexions sur le statut juridique des territoires et des communautés alliés, et sur le processus de romanisation", Hypothèses, 13, 1, 169-178.

Berthelet, Y. (2013), "Expiation, par Rome, de prodiges survenus dans les cités alliées du nomen latinum ou des cités alliées italiennes non latines", L'Antiquité Classique 82, 91109.

Breglia Pulci Doria, L. (1983), Oracoli Sibillini tra rituali e propaganda (Studi su Flegonte di Tralles), Napoli, Liguori Editori.

Brisson, L. (1986), "Neutrum utrumque. La bisexualité dans l'antiquité gréco-romaine”, en L'Androgyne, Paris, Albin Michel, 31-61.

Brisson, L. (1997), Le sex incertain. Androgynie et hermaphroditisme dans I'Antiquité grécoromaine, Paris, Les Belles Lettres.

Caerols, J. J. (1991), Los Libros Sibilinos en la historiografía latina, Madrid, Editorial Complutense.

Cantarella, E. (2002), Bisexuality in the Ancient World, New Haven CT, Yale University Press.

Cantarella, E. (2005), "The Androgynous and Bisexuality in Ancient Legal Codes", Diogenes, 52, 5, 5-14.

Cid López, R. M. (2007), "Las matronas y los prodigios. Prácticas religiosas femeninas en los 'márgenes' de la religión romana”, Norba, 20, 11-29.

Cousin, J. (1942-1943), "La crise religieuse de 207 av. J.-C.", RHR, 126, 15-41.

Crifò, G. (1999), Prodigium e diritto: il caso dell'ermafrodita, Index, 27, 113-120.

Champeaux, J. (1996), "Pontifes, haruspices et décemvirs. L'expiation des prodiges de 207", REL, 74, 67-91.

Dasen, V. (2005), "Blessing or portents? Multiple births in ancient Rome", en K. Mustakallio, J. Hanska, H.-L. Sainio, V. Vuolanto (éds.), Hoping for continuity. Childhood, education and death in Antiquity and the Middle Ages (Acta Instituti Romani Finlandiae XXXIII), Rome, 72-83.

Delcourt, M. (1958), Hermaphrodite. Mythes et rites de la bisexualité dans l'antiquité classique, Paris, PUF.

Delcourt, M. (1966), Hermaphroditea. Recherches sur l'être double promoteur de la fertilité dans le monde classique (Coll. Latomus 86), Bruxelles, Latomus.

Doroszewska, J. (2013), "Between the monstrous and the Divine: Hermaphrodites in Phlegon of Tralles' Mirabilia”, Acta Ant. Hung, 53, 379-392.

Freyburger, G. (1977), "La supplication d'actions de grâces dans la religion romaine archaïque", Latomus, 36, 283-315.

Freyburger, G. (1988), "Supplication grecque et supplication romaine", Latomus, 47, 3, 501525. 
Garland, R. (1995), The Eye of the Beholder. Deformity and Disability in the Graeco-Roman World, London, Duckworth.

Graumann, L. A. (2013), "Monstrous Births and Retrospective diagnosis: the case of Hermafrodites in Antiquity", en Chr. Laes, C.F. Goodey, M. Lynn Rose (eds.), Disabilities in Roman antiquity: disparate bodies, a capite ad calcem (Mnemosyne, supplements. History and archaeology of classical antiquity, 356), Leiden-Boston, Brill, 181-210.

Guittard, Ch. (2004), "Les prodiges dans le livre XXVII de Tite-Live", Vita Latina, 170, 56-81. Halkin, L. (1953), La supplication d'action de grâces chez les Romains, Paris, Les Belles Lettres.

Lake, A. K. M. (1937), “The Supplicatio and Graecus Ritus”, en R.P. Casey, S. Lake- A.K. Lake (eds.), Quantulacumque: Studies Presented to Kirsopp Lake, London, Christophers, 243-251.

Louis, P. (1975), Monstres et monstruosites dans la biologie d'Aristote, en J. Bingen, G. Cambier, G. Nachtergael (éd.), Le monde grec: pensée, litterature, histoire, documents. Hommages à Claire Préaux, Bruxelles, Éditions de I'Université de Bruxelles, 277-284.

Mac Bain, B. (1982), Prodigy and expiation: a study in Religion and Politics in Republican Rome (Coll. Latomus 117), Bruxelles, Latomus.

Maiuri, A. (2012), "Deformità e difformità nel mondo greco-romano", en M. Passalacqua, M. De Nonno, A. M. Morelli (a cura di), Venuste noster. Scritti offerti a Leopoldo Gamberale (Spudasmata 147), Zurich, Georg Olms Verlag, 526-547.

Maiuri, A. (2013), "Il lessico latino del mostruoso", en I. Baglioni (a cura di), Monstra. Costruzione e Percezione delle Entità Ibride e Mostruose nel Mediterraneo Antico (Religio Collana di Studi del Museo delle Religioni "Rafaele Pettazzoni"), Roma, Quasar, Vol.II, 167-177.

Mazurek, T. (2004), "The decemviri sacris faciundis: supplication and prediction", en C.F. Konrad (ed.), Augusto augurio. Rerum humanarum et divinarum commentationes in honorem Jerzy Linderski, Stuttgart, Steiner Verlag, 151-168.

Mineo, B. (2000), "L’anneé 207 dans le récit livien", Latomus, 52, 512-540.

Monaca, M. (2005), La Sibilla a Roma. I libri sibillini fra religione e politica, Cosenza, Giordano.

Montero, S. (1993), "Los harúspices y la moralidad de la mujer romana”, Athenaeum. 81, 647-658. Montero, S. (1994), Diosas y adivinas. Mujer y adivinación en la Roma antigua, Madrid, Trotta.

Montero, S. (2008), "La supplicatio expiatoria como factor de cohesión social", en N. Spineto (a cura di), La religione come fattore di integrazione: modelli di convivenza e di scambio religioso nel mondo antico. Atti del IV Convegno Internazionale del Gruppo di Ricerca Italo-Spagnolo di Storia delle Religioni Università degli Studi di Torino (29-30 sept. 2006), Alessandria, Edizioni dell'Orso.

Moussy, C. (1977), "Esquisse de l'histoire de monstrum”, RÉL, 55, 345-369.

Péter, O. M. (2001), "Olim in prodigiis nunc in deliciis. Lo status giuridico dei monstra nel diritto romano”, en G. Hamza, F. Benedek (hrsg.), Iura antiqua-lura moderna. Festschrift für Ferenc Benedek zum 75. Geburtstag, Pecs, Dialóg Campus Kiadó, 207-216.

Sandoz, L. Ch. (2008), "La survie des monstres: ethnographie fantastique et handicap à Rome, la force de l'imagination", Latomus, 68, 21-36.

Scheid, J. (1988), "Les livres Sibyllins et les archives des quindecémvirs", en C. Moatti (ed.), La mémoire perdue. Recherches sur l'administration romaine, Paris, École Française de Rome, 11-26.

Schulz, C. E. (2006), Women's Religious Activity in the Roman Republic, Chapel Hill, University of North Carolina Press. 
Segarra, D. (2005), "La arboricultura y el orden del mundo: de Vertumnus al 'Dios' que planta e injerta", en R. Olmos, P. Cabrera, S. Montero (eds.), Paraíso cerrado, jardín abierto: el reino vegetal en el imaginario del Mediterráneo, Madrid, Polifemo, 207-232. Segarra, D. (2006), "'Arboricoltori sacri'. L'operato degli aruspici nella sfera vegetale", en M. Rocchi, P. Xella, J. A. Zamora (a cura di), Gli operatori cultuali, Atti del II Incontro di studio organizzato dal "Gruppo di contatto per lo studio delle religioni mediterranee" (Roma, 10 - 11 maggio 2005), Verona, Essedue.

Trentin, L. (2011), "Deformity in the Roman Imperial Court", G\&R, II S., 58, 195-208.

Vallar, S. (2013), "Les hermaphrodites I'approche de la Rome antique", RIDA, 60, 201-217. 